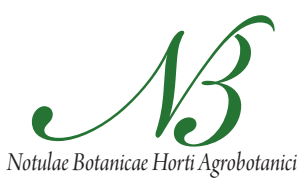

Cluj-Napoca

\title{
Polymorphism in Random Amplified and Nuclear rDNA Sequences Assessed in Certain Apple (Malus $\times$ domestica Borkh.) Cultivars
}

\author{
Miłosz SMOLIK*, Katarzyna MALINOWSKA, Beata SMOLIK, Krzysztof PACEWICZ \\ West Pomeranian University of Technology, Stowackiego 17, 71-434 Szczecin, Poland; msmolik@zut.edu.pl (*orresponding author)
}

\begin{abstract}
Eigth apple (Malus $\times$ domestica Borkh.) cultivars: 'Delikates', 'Cortland', 'James Grieve', 'Lired', 'Jonathan', 'Golden Delicious', 'Jonagold' and 'Idared' were characterized by two different molecular tools. These included analysis of the distribution of RAPD markers and length variability of the SSU, 5.8S, LSU and ITS region of the nuclear rRNA genes assessed in PCR reactions with different combinations of 'universal' primers. RAPD analysis was performed with 17 out of 24 RAPD primers tested. Those amplified a total of 183 loci (872 amplicons) out of which 34 (18.5\%) were monomorphic, 128 (69.5\%) were polymorphic and 22 (12\%) cultivar-specific. Cultivar-specific RAPD products were detected for each apple cultivar. Amplification of the rDNA sequences showed variability. Fifty-four amplicons were generated in the experiment including 14 monomorphic, 26 polymorphic, and 14 cultivar-specific products. Altogether 232 amplicons were generated, whose length ranged from 220 to $940 \mathrm{bp}$. The analysis of dendrograms constructed on the basis of the analysis of RAPD genetic profiles and profiles amplified on rDNA matrices showed their significant correlation (Mantel test: $r(A B)=0.430$; p-value (Two-tailed) $=0.024$ ), which proves that the used methods correctly presented variability within the examined cultivars, and the molecular markers identified in the study can be considered appropriate.
\end{abstract}

Keywords: apple cultivars, Malus, Mantel test rDNA, RAPD, variability

\section{Introduction}

Apple (Malus $\times$ domestica Borkh.), together with many economically significant fruit plants growing in the temperate zone, belongs to the family Rosaceae (King et al., 1991).

The genus Malus Mill. comprises from 25 to as many as 47 species, and the number has been changing and depends on the possibility of approval of new species or hybrids (van Treuren et al., 2010; Yan et al., 2008).

Apple is a species that is highly diversified in terms of morphological, phenological and genetic traits (among other things genotype polyploidy) (Zhou and Li, 1999). Many studies on the genus Malus have been conducted. They included studies on the use of molecular tools to identify cultivars and rootstocks, to construct genetic maps, and in marker assisted selection (MAS), using various types of markers: RAPD (Royo and Itoiz, 2004; Sestras et al., 2009; Zhou and Li, 2000), SSR (van Treuren et al., 2010) or ISSR (Goulão and Oliveira, 2001; Smolik and Krzysztoszek, 2010).

rDNA sequences have become a subject of numerous experiments. Nuclear rDNA are grouped into arrays consisting of hundreds to thousands of tandem repeats. This region includes two spacers (ITS1 and ITS2) that separate the SSU (18S), $5.8 S$ and LSU (26S) of nuclear ribosomes genes (Baldwin, 1992). ITS sequence data have been extensively documented to provide insights into phylogenetic history, polyploidy ancestry, genetic relationships and fingerprinting (Álvarez and Wendel, 2003).

There are many studies in the scientific literature where authors describe genetic variability of various types of sequences (including rDNA) and base the interpretation of results on the significance of correlation coefficient between the genetic similarity matrices calculated for the variability described within the examined sequences. In the case of a significant correlation, the described results gain in value. During analysis of rDNA sequences, variability per se within them should be taken into account together with variability resulting from the occurrence of rDNA fragments polymorphic in length (e.g. additional ITS amplicons), especially in polyploid genotypes (Smolik et al., 2010, 2011). Using different pairs of 'universal' primers in the PCR analysis, it is possible to amplify products of different length in a reaction with only one pair of 'universal' primers. It may be difficult to choose an amplicon representative for rDNA sequences for sequencing and further analyses. Therefore, a question arises whether selecting a definite amplicon for sequencing and disregarding others introduces a too considerable error into the results of the analyses. The scientific literature on the taxonomy of subjects based on the analysis of rDNA sequences does not provide full explanation if one reaction product, characteristic of the genus (e.g. ITS), or a mixture of e.g. ITSs of different length, was taken into consideration in the sequencing of regions/products. 
Therefore, the aims of the present study were; to identify the genotypic variability between eight apple cultivars ('Delikates', 'Cortland', 'James Grieve', 'Lired' and 'Jonathan', 'Golden Delicious', 'Jonagold' and 'Idared') using RAPD technique, to describe the variability between the cultivars on the basis of DNA profiles obtained as a result of amplification of additional rDNA products, generated in reactions with various combinations of pairs of 'universal' primers, and to conduct the analysis of correlation of the genetic similarity matrices obtained in the analysis of variability of random DNA and rDNA sequences.

\section{Materials and methods}

Eight apple cultivars; 'Delikates', 'Cortland', 'James Grieve,' 'Lired', Jonathan', 'Golden Delicious', 'Jonagold' and 'Idared' from the collection of the Fruit Growing Research Station in Rajkowo of the West Pomeranian University of Technology in Szczecin were used in this study.

\section{DNA preparation}

Total DNA was extracted from fresh leaves. Plant material $( \pm 100 \mathrm{mg})$ was ground in liquid nitrogen with a mortar and pestle and incubated at $37^{\circ} \mathrm{C}$ with Protease K. The DNA extraction was described in Genomic Mini AX Plant protocol (A\&A Biotechnology Gdynia-Poland). RNaseA (Sigma-Aldrich) was added ( $2 \mu \mathrm{l})$ to the DNA samples to eliminate RNA contaminations by incubation at $37^{\circ} \mathrm{C}$ for $10 \mathrm{~min}$. Genomic DNA was quantified (GeneQuant DNA/RNA Calculator-Pharmacia LKB) to obtain 50 ng DNA pro $1 \mu$ lof DNA template.

\section{RAPD amplification}

PCR amplifications were performed with a set of 24 random primers-part of Operon kits (Operon Technologies USA). Reaction mixture $(25 \mu \mathrm{l})$ contained $10 \times$ PCR buffer with $\left(\mathrm{NH}_{4}\right)_{2} \mathrm{SO}_{4}, 2 \mathrm{mM}$ of dNTPs, 25 $\mathrm{mM} \mathrm{MgCl} 2,2.5 \mu \mathrm{M}$ of primer, lu of Taq DNA polymerase enzyme (Fermentas MBI) and 50 ng of template DNA. The reactions were performed in Mastercyckler 5333 (Eppendorf). The program of thermal cycling was as follows: initial activation step at $95^{\circ} \mathrm{C}$ for $1.5 \mathrm{~min}$ followed by 40 cycles of $1 \mathrm{~min}$ at $94^{\circ} \mathrm{C}, 1 \mathrm{~min}$ at $36^{\circ} \mathrm{C}$ and $2 \mathrm{~min}$ at $72^{\circ} \mathrm{C}$, with a final extension step at $72^{\circ} \mathrm{C}$ for 10 min. The amplification was concluded by a final extension at $72^{\circ} \mathrm{C}$ for $5 \mathrm{~min}$.

\section{rDNA. Oligonucleotides for PCR amplifications}

The analysis encompassed nuclear rDNA, including the following sequences: SSU, ITS1; 5.8S; ITS2 and LSU. The general structure and the arrangement of the analyzed sequences encoding the formation of rRNA genes are presented in Fig. 1. The figure also includes names, approximate locations and directions of the hybridizations of primers used for PCR reactions. The origin of primers, sequences and their authors are presented in Tab. 1 .

Tab. 1. rDNA sequence targeted PCR primers used in this study

\begin{tabular}{ccc}
\hline $\begin{array}{c}\text { rDNA fragment } \\
\text { amplified }\end{array}$ & Primer's name & Author(s) \\
\hline SSU & NS1, NS2, NS4, NS3 & White et al., 1990 \\
& NS5, ITS2, ITS5, ITS1 & White et al., 1990 \\
ITS1 & 5.8S, & Vilgalys and Hester*, 1990 \\
& SR6R & Gardes and Bruns, 1993 \\
& ITS1-F & White et al., 1990 \\
ITS2 & ITS3, ITS4 & Vilgalys and Hester, 1990 \\
LSU & ITS4-B, 5.8SR & Vilgalys and Hester, 1990 \\
\hline
\end{tabular}

${ }^{*}$ Vilgalys unpublished [http://www.botany.duke.edu/fungi/mycolab]

\section{$P C R$ amplification of $r D N A$ sequences}

PCR mixtures $(25 \mu \mathrm{l})$ contained $10 \times \mathrm{PCR}$ buffer with $\left(\mathrm{NH}_{4}\right)_{2} \mathrm{SO}_{4}, 2 \mathrm{mM}$ dNTPs and $25 \mathrm{mM} \mathrm{MgCl}, 1.0$ units of Taq DNA polymerase (Fermentas MBI), $2.5 \mu \mathrm{M}$ of each primer and $100 \mathrm{ng}$ of template DNA. DNA was amplified using a Mastercycler 5333 (Eppendorf) thermocycler and using the following program: initial denaturation at $94^{\circ} \mathrm{C}$ for $7 \mathrm{~min}, 40$ cycles of $30 \mathrm{~s}$ at $94^{\circ} \mathrm{C}$, annealing temperature, $2 \mathrm{~min}$ at $72^{\circ} \mathrm{C}$ and $7 \mathrm{~min}$ at $72^{\circ} \mathrm{C}$ for a final extension. The annealing temperature was usually adjusted according to the $T_{m}$ of the primers being used in the reaction (Tab. 1). Amplifications were performed according to the touchdown PCR protocol by raising the temperature of the first singles cycles by $6^{\circ} \mathrm{C}$ above the annealing temperature, adopted from the preliminary experiments for both primers.

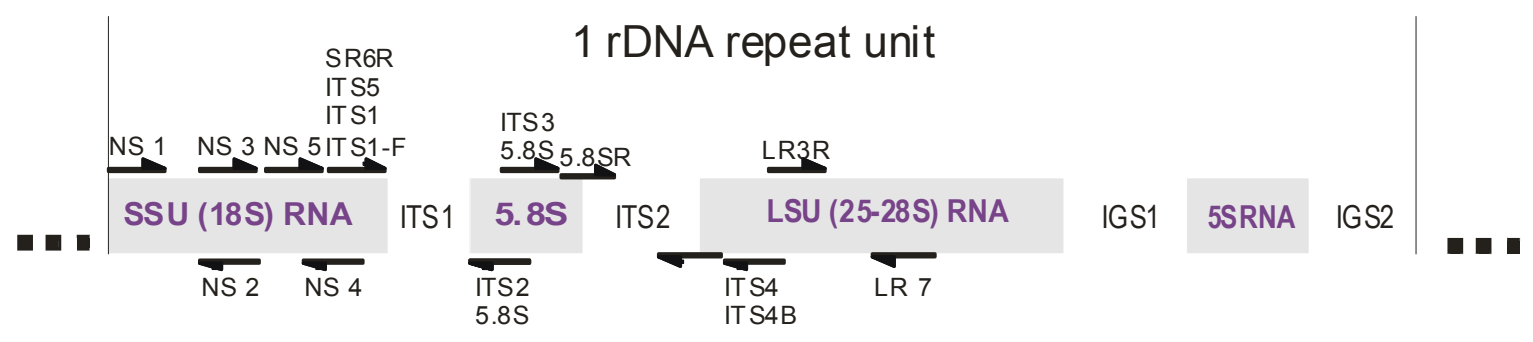

Fig. 1. rDNA unit. Arrows indicate aproximate positions of primers used to generate amplicons in different rDNA regions. Primer's names, sequences and they authors were listed in Tab. 1 
266

\section{Electrophoresis and data analysis}

PCR products were separated by electrophoresis on a $1.5 \%$ agarose (Basica LE-Prona) in $1 \times$ TBE buffer, then stained with $\mathrm{EtBr}$ and visualized (MiniBIS Pro-DNR Bio-Imagining System-Israel). O'RangeRuler 200 bp DNA Ladder (Fermentas MBI) was used as a size marker (3000-200 bp). RAPD and rDNA products were scored as 1 (present) or 0 (absent) for the cultivar and similarity index matrices were generated based on number of shared fragments. The similarity coefficient between accessions compared was determined by Jaccard's coefficient (Nei and $\mathrm{Li}, 1979)$. Similarity matrices were generated using the PhylTool software (Buntjer, 2001) and were compared

Tab 2. Cultivar-specific RAPD products generated for eight apple cultivars

\begin{tabular}{|c|c|}
\hline Cultivars & $\begin{array}{l}\text { Cultivar-specific RAPD products } \\
\text { and their lengths in bp }\end{array}$ \\
\hline ‘Cortland’ & 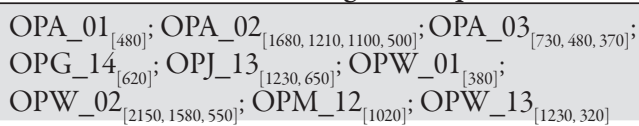 \\
\hline 'Delikates' & $\begin{array}{l}\text { OPA_01 } \\
\text { OPW_11760,890] }\end{array}$ \\
\hline $\begin{array}{l}\text { 'James } \\
\text { Grieve' }\end{array}$ & 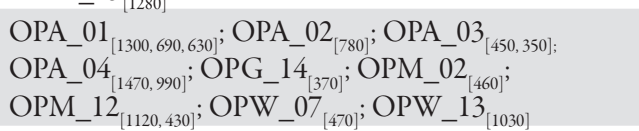 \\
\hline 'Lired' & $\begin{array}{l}\text { OPA_01 } \\
\text { OPJ_01 }{ }_{[330]} ; \text { OPA_02 } 2_{[330]} ; \text { OPM_0PA03 } \\
\text { OPM_12 } 2_{[430]} ; \text { OPW_09 }{ }_{[1960,1210]} ; \text { OPW_13 }{ }_{[360]} ;\end{array}$ \\
\hline 'Jonathan' & 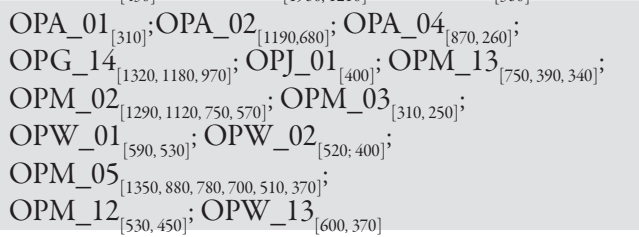 \\
\hline $\begin{array}{l}\text { 'Golden } \\
\text { Delicious' }\end{array}$ & 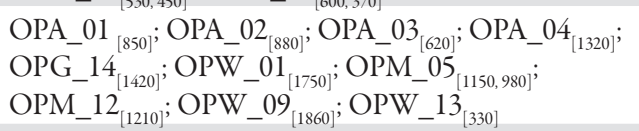 \\
\hline 'Jonagold' & 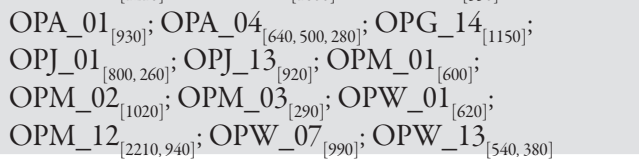 \\
\hline 'Idared' & OPA_03 ${ }_{[520240]} ;$ OPA_04 $4_{[2060)} ;$ OPM_01 $1_{[320]}$ \\
\hline
\end{tabular}

by calculating the product-moment correlation (Pearson) between matrices and the Mantel (Daniel's) test statistic (Z) of significance using the XLSTAT subprogram. The relationships between the eight cultivars were presented graphically. The strength of the internal branches from the resulting tree was tested by TREECON bootstrap analysis application using 2,000 pseudoreplications (Felsenstein, 1985; van de Peer and de Wachter, 1994).

\section{Results}

Randomly amplified DNA (RAPD) and rDNA length polymorphism showed that the eight apple cultivars exhibited a relatively wide range of variability. The analysis of genetic profiles revealed that the range of variability, determined with the use of each of the methods separately, was similar. In the both methods, polymorphic and cultivarspecific products were amplified. Variability (length polymorphism) was found within rDNA sequences, presented as amplicons polymorphic in terms of length, generated in reactions with different pair combinations of 'universal' primers.

\section{RAPD-Random Amplified Polymorphic DNA}

Twenty-four primers were used in reactions, generating $17-465$ amplicons. The range of variability was assessed on the basis of 232 products, of which 112 were polymorphic, 114 were cultivar-specific, and 6 were monomorphic. On average from 43 ('Idared') to 71 ('Jonagold') products were generated for the examined apple cultivars. Their length ranged from 2780 (OPM_05) to 220 bp (OPM_03).

\section{Polymorphic loci}

The greatest number of products (22) was amplified in a reaction with primer OPA_03, and the least-5, respectively: with primers OPJ_13, OPW_07, and 7 in reactions with each of the primers: OPM_02 and OPM_01_1.

\section{Cultivar-specific loci}

One hundred fourteen polymorphic and cultivar-specific RAPD products (Tab. 2) were amplified for the eight apple cultivars (Fig. 2).

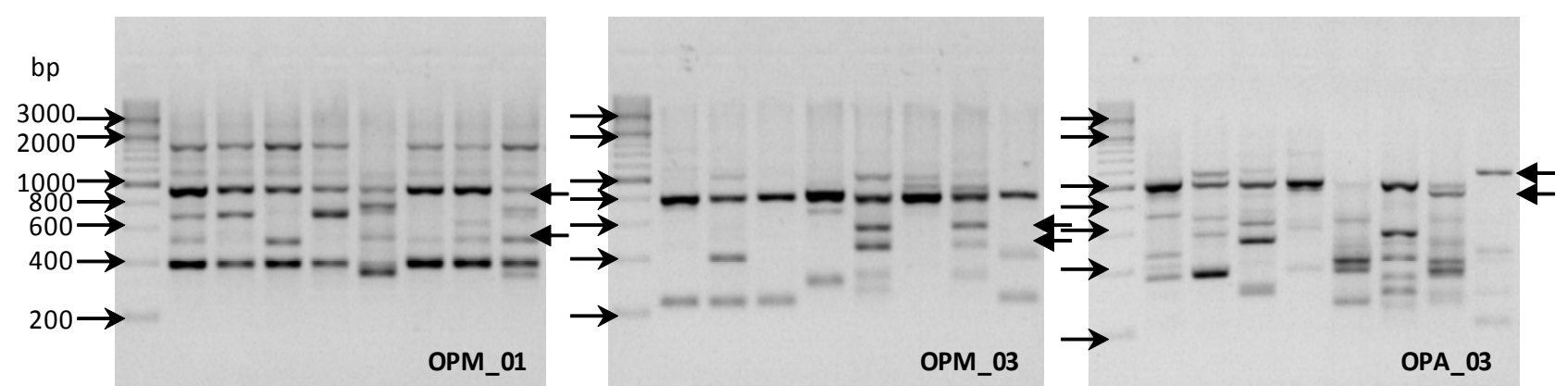

MW-Molecular Weight (O’RangeRuler 200bp DNA Ladder), 1-'Cortland', 2-'Delikates', 3-'James Grive', 4-'Lired', 5-'Jonathan', 6-'Golden Delicious', 7-'Jonagold', 8-'Idared

Fig. 2. PCR products profiles generated in amplifications with selected RAPD primers. Arrows mark selected polymorphic PCR product 
The greatest number (32) was amplified in amplifications with 13 primers for 'Jonathan', and the least (4)-with 4 primers for the cultivar 'Idared' (Tab. 2).

\section{rDNA sequences}

In the initial experiments, 28 universal primer pairs were used, of which in amplifications with 17 primer pairs combinations, distinct products were generated that differed in length and hybridization sites within the rDNA sequences (Tab. 1, Fig. 1). A total of 44 PCR products were generated of which $20(46 \%)$ were polymorphic, $13(29 \%)$ were monomorphic and 11 (25\%) were cultivar-specific (data not shown). Amplicons (193) of the length ranging from $\sim 1000$ (NS5+ITS2) to 220 bp (SR6R+5.8S) were generated for the examined cultivars. The greatest number of polymorphic products (4) was found after using primer pair SR6R+5.8S. The amplified products were from $\sim 640$ to $\sim 220$ bp long. Cultivar-specific products (11) were generated in reactions with the different primer combinations and were listed in Tab. 3 and Fig. 3. More than 12 monomorphic products were amplified, present in all the examined apple cultivars. They were obtained by the amplification of each of characterized rDNA sequences (Fig. 1,3).

\section{SSU}

Two primer pairs (NS1+NS2, NS3+NS4) and partially NS5+5.8S were used for amplification of SSU region. In PCR with primer combinations: NS1+NS2 and NS3+NS4 one (530 bp) and two monomorphic products were amplified, respectively (Tab. 3, Fig. 3).

Tab 3. Apple cultivar-specific products generated in PCR reaction on rDNA templates

\begin{tabular}{|c|c|}
\hline Cultivar & $\begin{array}{l}\text { Primer's pair and lengths of } \\
\text { amplified amplicons (bp) }\end{array}$ \\
\hline 'Cortland' & $\mathrm{NS5}+5.8 \mathrm{~S}_{[940]}$, SR6R $+5.8 \mathrm{~S}_{[220]}$, ITS5 + ITS $4_{[670]}$ \\
\hline 'James Grieve' & ITS1 + ITS2 \\
\hline 'Lired' & ITS1F + ITS2 $2_{[310]}$, ITS5 + ITS4 \\
\hline 'Jonathan' & ITS1_F + ITS2 \\
\hline 'Golden Delicious' & ITS1F + ITS2 \\
\hline 'Jonagold' & NS5 + ITS2 \\
\hline
\end{tabular}

ITS1

Combinations of eight primer pairs were used for amplification of the ITS1 sequence (Tab. 3). As a result, monomorphic (5), polymorphic (12) and cultivar-specific (10) products were amplified (Tab. 3, Fig. 3), presented in detail in Tab. 4.

\section{ITS (ITS1+5.8S+ITS2)}

The ITS sequences were amplified using combination of three primer pairs: ITS5+ITS4, ITS1_F+ITS4 and SR6R+ITS4 (Tab. 3). As a result, three monomorphic, polymorphic and one 'Lired' cultivar-specific product were amplified, respectively (Tab. 3, 4).

\section{ITS2}

The sequences of ITS2 spacer were amplified using three primer pairs combination (Tab. 3). As a result-four polymorphic and two monomorphic products were generated (Tab. 3, Fig. 3).

\section{LSU}

Monomorphic fragment (810 bp) of the LSU sequence was amplified in a reaction with primer pair LR3R and LR7 (Tab. 4).

\section{Genetic relationships. RAPD}

The analysis of topology of the constructed dendrogram enabled to distinguish two similarity groups corresponding to the pedigrees of two examined cultivars'Jonagold' and 'Delikates', respectively grouped as clusters 'a' and 'b' (Fig. 3). Group 'a' included the cultivars: 'Jonathan', 'Golden Delicious,' 'Jonagold' and 'Idared', and group 'b': 'Cortland,' 'Delikates', 'James Grieve' and 'Lired' (Fig. 3). The phylogenetic similarity between them ranged from 0.48 between the cultivar 'Idared' and 'Golden Delicious' to 0.19 between the cultivars 'Jonathan' and 'Cortland' (data not shown). The phylogenetic similarity of 0.32 was found between the cultivars 'Jonagold' and 'Jonathan', and the lowest similarity $(0.25)$ was found in the pedigree 'a' ('Jonagold') between the cultivars 'Idared' and 'Jonathan' (Fig. 3). The analysis of the topology of groups for pedigree

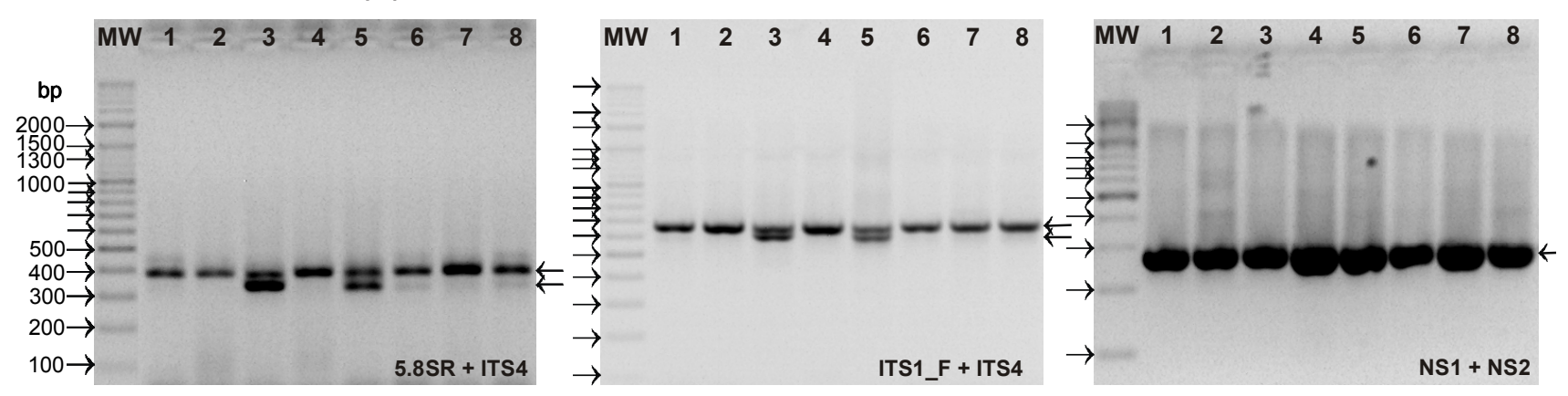

MW-Molecular Weight (O’RangeRuler 200bp DNA Ladder), 1-'Cortland', 2-'Delikates', 3-'James Grive', 4-'Lired', 5-'Jonathan', 6-'Golden Delicious', 7-'Jonagold', 8-'Idared'

Fig. 3. PCR products profiles generated in amplifications primers pairs designed for investigation of rDNA variability. Arrows mark selected monomorphic or polymorphic products 


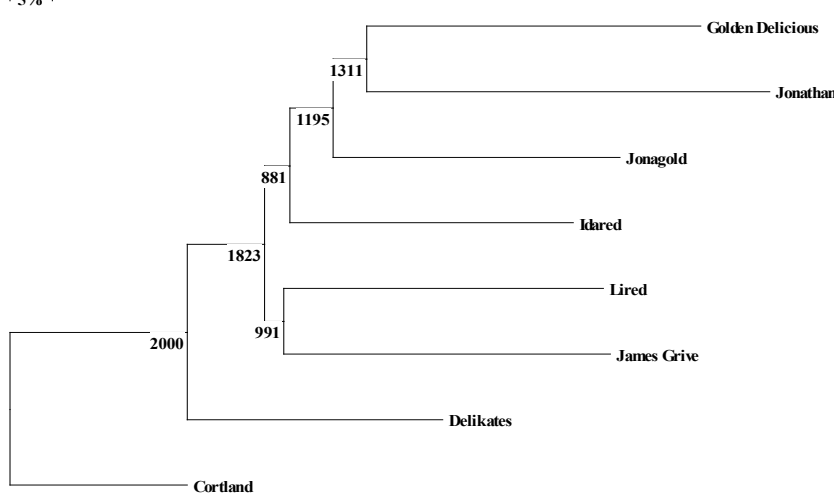

RAPD

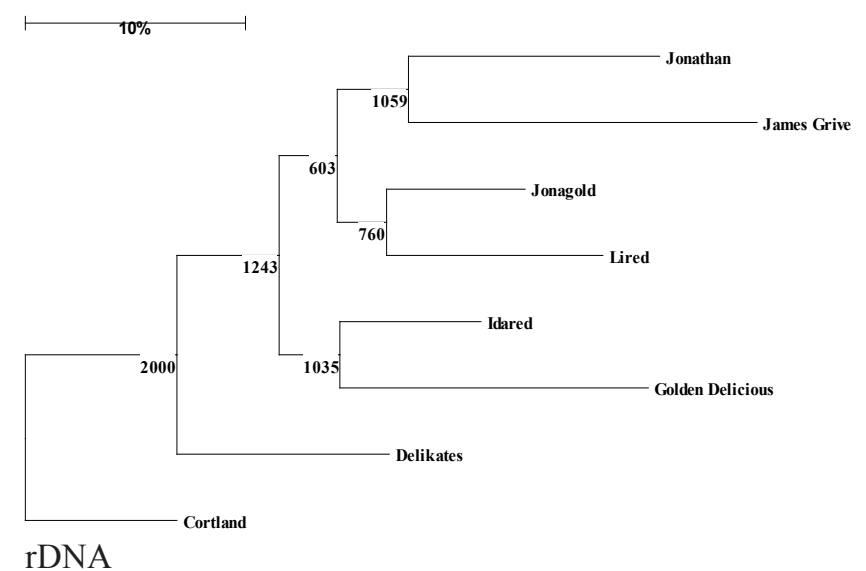

Fig. 4. UPGMA dendrogram based on similarity index representing genetic relationships among Malus cultivars analysed by PCR methods. Numbers indicate the real values of bootstraps in which the branch was observed in 2,000 pseudoreplications

'b' ('Delikates') revealed the highest similarity between the cultivars 'Cortland' and 'Delikates' (0.44), and the lowest (0.27) between 'Cortland' and 'James Grieve' (Fig. 4).

\section{$r D N A$}

Similar genetic relationships were found between the cultivars in the analysis of genetic profiles obtained after amplification of the rDNA sequences (Fig. 3). Genotype similarity ranged respectively from $63 \%$ between the cultivars 'Cortland' and 'James Grieve' and between 'Jonathan' and 'Cortland' to $86 \%$ between the cultivars 'Jonagold' and 'Idared'. In addition, significant correlation coefficient was found, assessed with the Mantel test $(\mathrm{r}(\mathrm{AB})=0.430$, $\mathrm{p}$-value (two-tailed $=0.024$ ) for the matrices of phylogenetic similarity calculated for the examined cultivars with the use of the RAPD technique and on the basis of the analysis of rDNA length polymorphism.

\section{Discussion}

The results of the present study did not differ from those obtained from such type of previous studies on various apple accessions, including cultivars, in terms of both the number of the used primers, and the range of length and structure of the amplified products: poly-, monomorphic or cultivar-specific (Sestras et al., 2009; Zhou and Li, 2000).

Hence a high percentage of polymorphic products, including cultivar-specific $(\sim 70 \%)$ was observed by Zhou and $\mathrm{Li}$ (2000) in their study of apple, Royo and Itoiz (2004) noted 82\%, and Goulão et al. (2001)-60\%. Forte et al. (2002) found $52 \%$ of polymorphic RAPD products (loci) for 72 apple accessions. It resulted in relatively low genetic similarity coefficients, presented by Zhou and $\mathrm{Li}$ (2000) for 21 apple accessions.

Royo and Itoiz (2004) presented similarity coefficients ranged from 0.3 to 1.0 and Adebayo et al. (2009) on average amounted to 0.65 . In the present study, genetic similarity coefficients for RAPD markers ranged from $0.27-$
0.40 for 'Delikates' and 0.25-0.48 for 'Jonagold' pedigrees, respectively. Additionally, it was proved that the dendrogram of phylogenetic similarity properly presented genetic relationships between the examined apple cultivars. The grouping of cultivars enabled to divide them depending on the origin to a described pedigree ('Delikates' and 'Jonagold'). The cultivar-specific RAPD products amplified in the described experiment can be used together with the products described for ISSR (Smolik and Krzysztoszek, 2010) as markers supporting determination of genetic identity of cultivars, and also in tree nursery production in order to control varietal purity, which, as it is proved by a study by Mogdil et al. (2005), is not without significance.

Multicopy structure of rDNA makes amplification highly efficient, especially on templates of diploid genomes, and becomes interesting on templates of polyploid genomes (including Malus). Amplified fragments were not too long, so, for example, the ITS sequence (ITS1+5.8S+ITS2) on average was about 700 bp long, apart from numerous exceptions, in whose genetic profiles there were additional amplification products probably resulting from the presence in the genome of, for example, shorter copies of rDNA-e.g. as in the tetraploid forms of Fagopyrum or accessions of Syringa (Smolik et al., 2010; 2011; Yasuo and Ohnishi, 1998; ).

The present study showed the possibility of amplification of additional products of reactions with pairs of 'universal' primers, intentionally combined in different ways, on the matrices of $\mathrm{rDNA}$ sequences. In reactions with ITS-flanking primers (ITS5+ITS4, ITS1_F+ITS4 and SR6R+ITS4), products of the length $\sim 700$ bp and additional amplicons were amplified, whose characterization is presented in Tab. 4. Among them one specific product was amplified-for the cultivar 'Lired' (ITS5+ITS4 ${ }_{[720]}$ ).

According to many authors, the ITS sequences, due to their variability level, provide enough information that can be used in identification of molecular markers or in phylogenetic analyses. It is not without significance that the sequences are inherited from both parents, they are 
variable in polyploids (Forte et al., 2002; Nalini et al., 2007; Saini et al., 2008) and with their help hybridity and introgression can be assessed (Baldwin, 1992).

Shen et al. (1998) stated that assessment of genetic variability in the ITS1 region can be used in the identification of species of a given organism and in determination of genetic origin of a plant. Studying on beet, they used 18 primers in PCR reactions that generated products of the length from 740 to $610 \mathrm{bp}$. The longest products were generated in reactions with the primers ITS2, ITS4 and ITS5 (740 bp each). Similar results were obtained from the present study. Eighteen universal primer pairs, out of 24 used, generated products easily identified on electrophoregrams. Three primers (ITS2, ITS4 and ITS5), used by Shen et al. (1998) in their study on beet, were also used in a study of apple, only in different combinations. Primer ITS2 was used in combinations with 4 other primers (NS5, ITS1, ITS 1 F and ITS5). Primer ITS4-in combinations with 5 other primers (ITS5, ITS_1F, SR6R, 5.8SR and ITS3), while primer ITS5 with the following primers: ITS2 and ITS4. The combinations comprising the above-mentioned primer pairs generated products of the length from 220 to 720 bp in PCR reactions. In a PCR reaction, where primer pair ITS5 + ITS4 was used, the longest generated product was the band of the length of $720 \mathrm{bp}$, which corresponded to the length of the products generated by these primers in a study of beet (740 bp).

The analysis of genetic similarity dendrogram constructed on the basis of genetic profiles obtained in PCR reactions (RAPD and $\mathrm{rDNA}$ ) showed that, similarly as in the ISSR technique (Smolik and Krzysztoszek, 2010), the examined cultivars were divided into two groups. One pedigree included the cultivar 'Delikates' and its parental forms 'Cortland', 'James Grieve', and 'Jonathan', and the second one 'Jonagold' and its parental forms 'Golden Delicious', 'Idared' (a hybrid of the cultivars 'Jonathan' and 'Wagner'), and the cultivar 'Lired' (a mutant deriving from the cultivar 'James Grieve').

It was proved that there is a deviation in the grouping of the cultivars presented on the dendrogram (rDNA). Two cultivars 'Jonathan' and 'Lired' were exchanged in the similarity group ' $a$ ' and ' $b$ '. Thus the cultivar 'Jonathan' was grouped together with the cultivars forming the pedigree of 'Delikates', and the cultivar 'Lired' was grouped with the cultivars of the 'Jonagold' pedigree. The other cultivars were grouped according to their origin. Different classification of the cultivars 'Jonathan' and 'Lired', as opposed to their already known origin, presumably is a result of the limited analyses. Their only results are of the analysis of genetic profiles obtained in reactions with 18 combinations of pairs of various universal primers. The values of genetic similarity are comparable to those presented in a study by Forte et al. (2002) for 72 apple accessions. These authors analysed polymorphism of rDNA sequences collected in the GeneBank database, and demonstrated a relatively wide range of variability. However, the range of variability in relation to grouping of genotypes on the dendrogram was consistent with the range of variability simultaneously determined using the RAPD technique.

Significant correlation coefficient was found, $[\mathrm{r}(\mathrm{AB})$ $=0.430$, p-value; two-tailed $=0.024)]$ assessed with the Mantel test, for genetic similarity matrices calculated on the basis of the analysis of RAPD and generated rDNA profiles. It should be mentioned that, according to Sneath and Sokal (1973), the calculated value of the correlation coefficient (significant) is too low. The authors state that in order to describe genetic similarity matrices as significantly correlated, the value of ' $r$ ' coefficient should be higher than 0.8. On the other hand, Lapointe and Legendre (1992) consider the matrices strongly correlated when $r \geq 0$.5.

\section{Conclusions}

The results of the present study confirm the suggestion of many authors on the existence of great variability potential of the genus Malus. However, it should be noted that statistically significant correlation between the genetic similarity matrices enables to state that the variability within the cultivars of two known pedigrees ('Delikates' and 'Jonagold') was correctly determined. Hence the already known (even though discussed) usefulness of the RAPD technique for determination of varietal distinctness was confirmed. What is more, the amplification of additional products on the rDNA templates demonstrated their length variability that is probably the presence of rDNA sequence copies of different length, and also the genetic potential of the genus Malus. The dendrogram constructed on the basis of the analysis of rDNA genetic profiles, despite it is significantly correlated with the RAPD dendrogram, may be a source of erroneous conclusions. The study confirms only the genetic potential of Malus and indicates the need for including ITS sequences also differing in copy length in the most frequent analyses.

\section{References}

Adebayo OL, Bola O, Opeyemi W, Gloria M, Temitope OO (2009). Phylogenetic and genomic relationships in the genus Malus on RAPDs. Afr J Biotechnol 8:3387-3391.

Álvarez I, Wendel JF (2003). Ribosomal ITS sequences and plant phylogenetic inference. Mol Phylogenet Evol 29:417434.

Baldwin BG (1992). Phylogenetic utility of the internal transcribed spacers of nuclear ribosomal DNA in plants: An example from the Compositae. Molec Phylogenet Evol 1:316.

Buntjer JB (2001). PHYLTOOLS Phylogenetic Computer Tools V. 1.32 for Win. Wageningen Agricultural University, 2001, The Netherlands.

Felsenstein J (1985). Confidence limits on phylogenesis: An approach using the bootstrap. Evolution 39:783-791. 
270

Forte AV, Ignatov AN, Ponomarenko VV, Dorokhov DB, Savelyev NI (2002). Phylogeny of the Malus (Apple Tree) species, inferred from the morphological traits and molecular DNA analysis. Russ J Genet 38(10):1150-1160.

Gardes M, Bruns TD (1993). ITS primers with enhanced specificity for Basidiomycetes-application to the identification of mycorrhizae and rusts. Mol Ecol 2:113-118.

Goulão L, Cabrita L, Oliveira CM Leitão JM (2001). Comparing RAPD and AFLP ${ }^{\mathrm{TM}}$ analysis in discrimination and estimation of genetic similarities among apple (Malus domestica Borkh.) cultivars. Euphytica 119:259-270.

Goulão L, Oliveira CM (2001). Molecular characterisation of cultivars of apple (Malus $\times$ domestica Borkh.) using microsatellite (SSR and ISSR) markers. Euphytica 122:8189.

King GJ, Alston FH, Batlle I, Chevreau E, Gessler C, Janse J, Lindhout P, Manganaris AG, Sansavini S, Schmidt H, Tobutt K (1991). The 'European apple genome map ping project'-developing a strategy for mapping gene coding for agronomic characters in tree species. Euphytica 56:89-94.

Lapointe FJ, Legendre P (1992). Statistical significance of the matrix correlation coefficient for comparing independent phylogenetic trees. Systematic Biology 41:378-384.

Modgil M, Mahajan K, Chakrabarti SK, Sharma DR, Sobti RC (2005). Molecular analysis of genetic stability in micropropagated apple rootstock MM.106. Sci Hort 104(2):151-160.

Nalini E, Bhagwat SG, Jawali N (2007). Identification and characterization of some ITS variants from hexaploid wheat (Triticum aestivum L.). Plant Sci 173:262-268.

Nei M, Li WH (1979). Mathematical model for studying genetic variation in terms of restriction endonucleases. Proc Nat Acad Sci USA 76:5269-5273.

Royo JB, Itoiz R (2004). Evaluation of the discriminance capacity of RAPD, isoenzymes and morphologic markers in apple (Malus $\times$ domestica Borkh.) and the congruence among classifications. Genet Res Crop Evol 51:153-160.

Saini A, Reddy SK, Jawali N (2008). Intra-individual and intraspecies heterogeneity in nuclear rDNA ITS region of Vigna species from subgenus Ceratotropis. Genet Res 90:299-316.

Sestras R, Pamfil D, Ardelean M, Botez C, Sestras A, Mitre I, Dan C, Mihalte L (2009). Use of phenotypic and MAS selection based on bulk segregant analysis to reveal the genetic variability induced by artificial hybridization in apple. Not Bot Horti Agrobo 37(1):273-277.

Shen Y, Newbury HJ, Ford-Lloy BV (1998). Identification of Taxa in the Genus Beta using ITS1 Sequence Information. Plant Mol Biol Report 16:147-155.
Smolik M, Krzysztoszek O (2010). Evaluation of genetic variability in chosen apple (Malus $\times$ domestica Borkh.) cultivars by ISSR-PCR analysis. Russ J Genet 46(7):923931.

Smolik M, Andrys D, Franas A, Krupa-Małkiewicz M, Malinowska K (2010). Polymorphism in Syringa rDNA regions assessed by PCR technique. Dendrobiology 64:5564.

Smolik M, Krupa-Małkiewicz M, Smolik B, Wieczorek J, Predygier K (2011). rDNA variability assessed in PCR reactions of selected accessions of Acer. Not Bot Horti Agrobo 39(1):260-266.

Sneath P, Sokal R (1973). Numerical taxonomy: The principles and practice of numerical classification. San Francisco, CA: Freeman WH.

van de Peer Y, De Wachter R (1994). TREECON for Windows: a software package for the construction and drawing of evolutionary trees for the Microsoft Windows environment. Comp Appl Biosci 10:569-570.

van Treuren R, Kemp H, Ernsting G, Jongejans B, Houtman H, Visser L (2010). Microsatellite genotyping of apple (Malus $\times$ domestica Borkh.) genetic resources in the Netherlands: application in collection management and variety identification. Genet Res Crop Evol 57(6):853-865.

Vilgalys R, Hester M (1990). Rapid genetic identification and mapping of enzymatically amplified ribosomal DNA from several Cryptococcus species. J Bacteriology 172:4238-4246.

White TJ, Bruns T, Lee S, Taylor J (1990). Amplification and direct sequencing of fungal ribosomal RNA genes for phylogenetics, p. 315-322. In: Innis M, Gelfand D, Sninsky J, White T (Eds.). PCR protocols: A guide to methods and application, Academic Press, San Diego.

Yan GR, Long H, Song WQ, Chen RY (2008). Genetic polymorphism of Malus sieversii populations in Xinjiang, China. Genet Res Crop Evol 55:171-181.

Yasuo Y, Ohnishi O (1998). Phylogenetic relationships among Fagopyrum species revealed by the nucleotide sequences of the ITS region of the nuclear rRNA gene. Genus Genet Syst 73:201-210.

Zhou ZQ, Li YL (1999). Evidence for the origin of Chinese soft apple. Asian Agri-History 3:35-37.

Zhou ZQ, Li YN (2000). The RAPD evidence for the phylogenetic relationship of the closely related species of cultivated apple. Genet Res Crop Evol 47:353-357. 